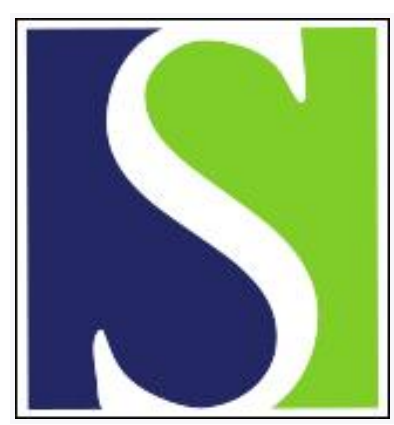

Scand J Work Environ Health 1991;17(5):330-336

https://doi.org/10.5271/sjweh.1694

Issue date: Oct 1991

Spectral analysis of sleep electroencephalography in rotating three-shift work.

by Åkerstedt T, Kecklund G, Knutsson A

Affiliation: Work Environment Unit, National Institute for Psychosocial Factors and Health, Stockholm, Sweden.

The following article refers to this text: 2011;37(1):62-69

This article in PubMed: www.ncbi.nlm.nih.gov/pubmed/1947919

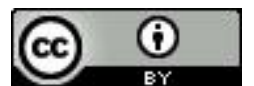




\title{
Spectral analysis of sleep electroencephalography in rotating three-shift work
}

\author{
by Torbjörn Åkerstedt, PhD, ${ }^{1,2}$ Göran Kecklund, MA, ${ }^{2}$ Anders Knutsson, $\mathrm{MD}^{3}$
}

\begin{abstract}
ÄKERSTEDT T, KECKLUND G, KNUTSSON A. Spectral analysis of sleep electroencephalography in rotating three-shift work. Scand J Work Environ Health 1991;17:330-6. Fourteen male rotating threeshift workers were subjected to 24-h ambulatory polysomnographic recording in connection with morning, afternoon, and night shift work (at home and at work). Total sleep time, stage 2, rapid-eye-movement sleep, and slow-wave sleep (stages $3+4$ ) were significantly reduced during sleep in connection with the night and morning shifts. Other visually scored sleep parameters and slow-wave energy (spectral power density integrated across sleep) were not affected. The content of the sleep cycles did not differ between shifts. The sleep before the morning shift was characterized by subjectively increased difficulties of sleep initiation and sleep termination, as well as by insufficient recuperation. The night shift was characterized by increased subjective difficulties of maintaining sleep, but also by increased ease of sleep initiation. It was concluded that both morning and evening shifts interfered with sleep, although no effects of sleep deprivation were found.
\end{abstract}

Key terms: power density, slow-wave activity, spectral analysis.

Shift work strongly interferes with sleep, at least if night work is involved $(1-8)$. In particular, day sleep after the night shift is reduced by several hours in comparison with the more normal sleep after the afternoon shift. The loss mainly affects stages 2 and REM (rapideye-movement) sleep, whereas SWS (slow-wave sleep, stages $3+4$ ) is usually unaffected. The effects on sleep in connection with the morning shift (work beginning around 0600 ) may be similar although we have found only one study including that shift (8).

Recently, it has been demonstrated that computer analysis of the low-frequency (delta) activity in electroencephalography (EEG) more sensitively reflects the homeostatic processes during sleep than does visually scored sleep stages 3 and $4(9,10)$. Such measures have never been used in studies of sleep in connection with shift work, and one purpose of the present study was to provide such data, using spectral analysis. Another purpose was to describe sleep in connection with the morning shift. A third purpose was to describe the subjective quality of shift-work sleep. To our knowledge prior studies have not combined polysomnographic and subjective measurements of shift-work sleep.

With respect to technique and design, most prior studies have used traditional polysomnography, involving stationary equipment and sleep in a laboratory, time in bed being allotted according to a predetermined schedule. The strange environment, the unfamiliar

\footnotetext{
1 Work Environment Unit, National Institute for Psychosocial Factors and Health, Stockholm, Sweden.

2 Department of Stress Research, Karolinska Institute, Stockholm, Sweden.

3 Occupational Health Unit, SCA Paper, Sundsvall, Sweden.
}

technicians, and the strict scheduling of sleep may have prevented truly spontaneous sleep/wake patterns from emerging. The present study was, therefore, designed for 24-h, ambulatory (work and home) polysomnography. This design allowed the subject spontaneous sleep in his own bed, and with accustomed privacy. We have used a similar approach in a prior study and found it feasible (7).

\section{Subjects and methods}

Fourteen male papermill workers between 25 and 55 years of age (mean age $=38.6$ years) participated in the study. The subjects participated in the earlier study by Torsvall et al (7), but the present recordings were carried out two years later. They belonged to the same work unit and received a modest economic compensation. All workers of the unit $(\mathrm{N}=40)$ were asked to participate, and $25(63 \%)$ initially agreed. Those who abstained did so because of "lack of time" or the perceived discomfort. In the present study a further 11 subjects were lost because of interference from their vacation schedule.

The worktask involved the handling of semi-automatic machinery and consisted of supervision (both directly and via visual display units) and minor repair work. The subjects worked a continuous three-shift system with clockwise rotation and shift changes at 0600,1400 , and 2200 . The sequence of morning (M), afternoon (A), and night (N) shifts and days off (x) (recorded shifts in italics) was as follows:

NNNNxxxMMxAAAAxxMMMMxA $A$ AxN $N$ Nxxxxxxx.

During three 24-h periods, containing the second of each of the three shifts, sleep was recorded on porta-
Reprint requests to: Professor T Ảkerstedt, IPM \& Stress Research, Karolinska Institute, Box 60205, S-104 01 Stockholm, Sweden. 
ble four-channel Medilog tape recorders. Half of the subjects were recorded in the first half of the shift cycle (the first three days in italics in the presented schedule), and the rest of the subjects in the second half of the shift cycle (the last three days in italics). Thus the same morning shift was used for recording in both halves of the group. The electrodes were attached and the recording started shortly before the work period. The subjects were encouraged to follow their normal habits of work, sleep, and leisure-time activities. The equipment was removed prior to the next work period $24 \mathrm{~h}$ later. As a check on sleep/wake behavior and other factors of interest, all of the subjects also kept a diary in which they entered sleep hours, sleep quality estimates, and drug intake for a two-week period. All the subjects agreed to refrain from alcohol consumption for $36 \mathrm{~h}$ before a recording.

Sleep was recorded with the use of a $\mathrm{C}_{2}-\mathrm{O}_{z}$ derivation for the EEG, and an oblique derivation for the electrooculography. Electromyography was not feasible since it interfered too much with normal functioning and social interaction. We have found that omitting the electromyography does not affect the total amounts of REM sleep although the onset may be delayed by $1-2$ min. The $\mathrm{C}_{z}-\mathrm{O}_{z}$ derivation yields higher delta amplitudes than standard sleep derivations (11), and after extensive laboratory testing we decided to adjust amplitude criteria for visual delta scoring to $100 \mu \mathrm{V}$ since this procedure yielded sleep stage data within a few percent of those of the recommended derivation $\mathrm{C}_{4}-\mathrm{A}_{1}$.

The EEG recordings were scored by two researchers (interrater reliability $0.79-0.82$ ) in accordance with the criteria of Rechtschaffen \& Kales (12). For the spectral analysis (fast fourier transform) the EEG was sampled at a frequency of $128 \mathrm{~Hz}$ with the use of conventional filter settings (band pass $0.35-70 \mathrm{~Hz}$ ). Epochs with artifacts or waking were removed according to the visual scoring. The fast fourier transform analysis was based on 7.5-s epochs, yielding a band width of $0.133 \mathrm{~Hz}$. The resulting spectral power density was integrated across the $0.5-3.9 \mathrm{~Hz}$ (delta) band, which seems to be highly responsive to sleep loss (10). The integrated value per epoch was then averaged across each minute of sleep.

So that summary statistics could be produced, the (integrated) values of the spectral power density per minute were averaged across each non-REM-REM sleep cycle to form "slow-wave activity" (SWA) per cycle. They were also accumulated across time to form "slow wave energy" (SWE) per cycle, as well as per completed sleep episode. The non-REM-REM sleep cycle was defined as the time from the first uninterrupted 5-min period of non-REM sleep to the end of REM sleep. (No sleep onset REM episodes occurred.)

So that the large interindividual variability between the SWA and SWE could be reduced, these variables were expressed relative to base-line sleep (ie, the sleep following the afternoon shift). For the SWE the total amount accumulated during this sleep stage was set at $100 \%$. For SWA, it was not practical to use the same reference, as the resulting values would have become minuscule. Instead, and in accordance with the procedure of Dijk et al (13), we used the mean SWA of the four cycles of the sleep after the afternoon shift.

The sleep diary contained questions on the timing and quality of sleep. The sleep quality ratings were given values between 1 and 5 , the latter being the most positive. The response alternatives had the following verbal anchors at the extremes (with a neutral or moderate rating in the middle): sleep quality: "very poor" - "very good"; ease falling asleep: "very easy" - "very difficult"; ease awakening: "very easy" _ "very difficult"; well rested: "not at all" - "very much"; restless sleep: "not at all" - "very"; too early an awakening: "not at all" - "much too early." Spontaneity of awakening had only two alternatives, "spontaneous" and "other cause" (alarm, noise, etc), which were given scores of 1 and 0 , respectively.

Since the FFT variables showed large differences in variance between shifts, we used nonparametric statistics to analyze the differences between conditions [ie, the Friedman analysis of variance by ranks (14)]. For simplicity and comparability the same procedure was used for all the other variables. For pairwise testing we used the procedure of the Friedman analysis of variance for making multiple comparisons subsequent to a significant overall effect (14). The test statistic in this case was the difference in accumulated rank between the members of a pair $(\partial R)$.

\section{Results}

Table 1 shows that, of the EEG variables, total sleep time differed significantly between shifts, with a maximum for the afternoon shift and a minimum for the morning shift. Very similar results were obtained for stage 2, REM sleep, and SWS. For total sleep time, stage 2, and REM sleep both the morning and night shifts showed significantly lower values than those of the afternoon shift $(\partial R \geq 12.7, P<0.05)$. None of the pairwise comparisons between the night and morning shifts were significant $(\partial R<12.7)$.

Sleep efficiency (total sleep time/time in bed), waking after sleep onset (waking/sleep period time), sleep latency (to stage 1), REM latency, SWS latency, and the nap measures did not differ significantly between the shifts. The naps were started at 1519 (SE $93 \mathrm{~min}$ ) after night work (four subjects) and at 1529 (SE $85 \mathrm{~min}$ ) after morning work (four other subjects). Only one subject napped in connection with the afternoon shift.

The subjective ratings showed a significant difference between shifts for sleep length, ease of falling asleep, ease of awakening, being well rested, early awakening, and spontaneity of awakening. In particular, the morning shift was associated with a significantly decreased sleep length, increased difficulties 
Table 1. Mean and standard error (SE) for parameters of sleep in connection with afternoon, morning, and night workshifts. ${ }^{a, b}$ (SWS = slow-wave sleep, REM = rapid-eye-movement, SWE = slow-wave energy)

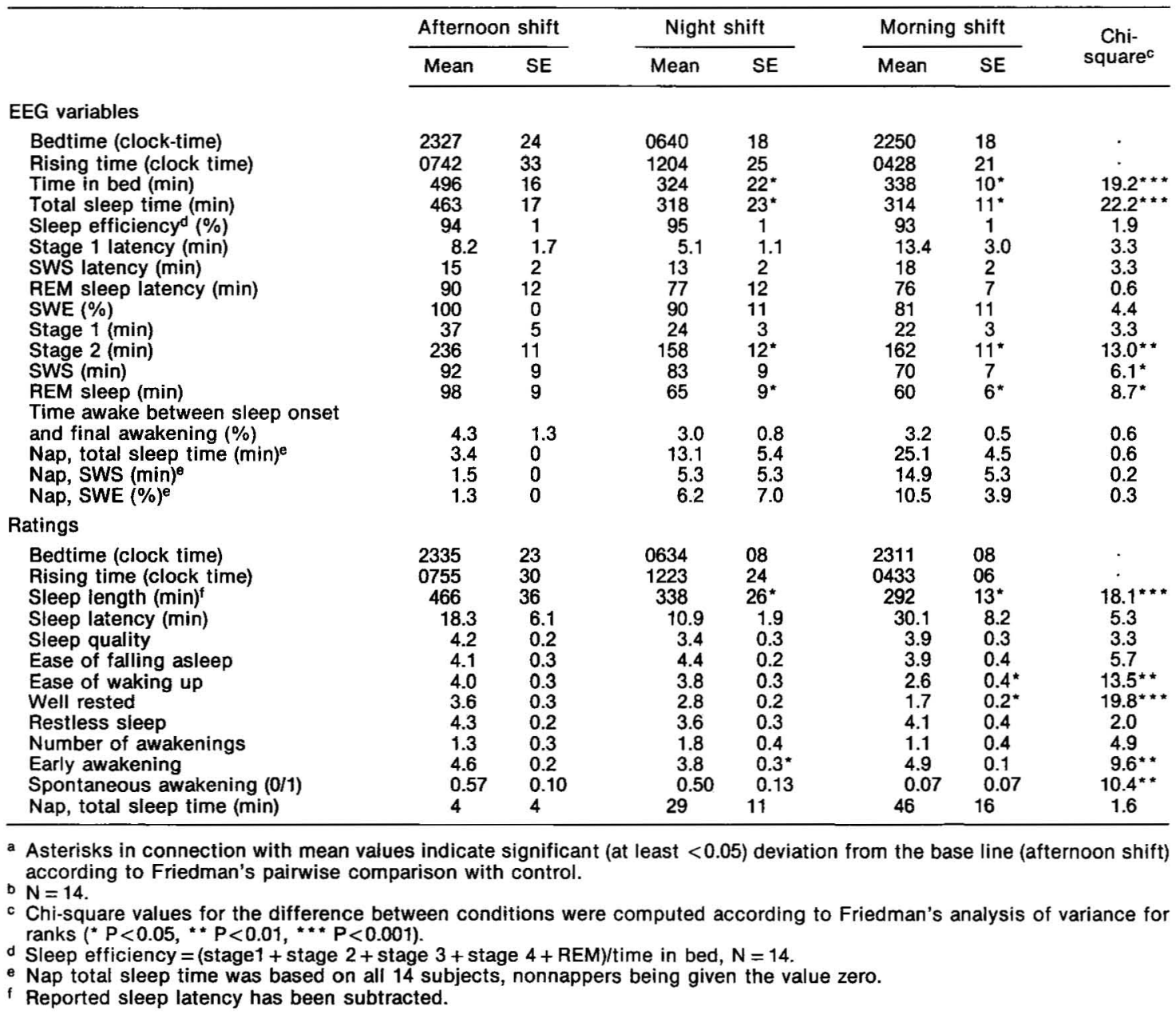

in awakening, and a decreased feeling of being well rested. The night-shift sleep was also rated as short and showed significantly more early awakenings. The pairwise comparison between sleep after the morning and night shifts showed significantly $(\partial \mathrm{R} \geq 12.7, \mathrm{P}<.0 .05)$ greater ease of waking up and of being well rested for the night-shift sleep. Sleep quality and restless sleep did not differ significantly between the three shifts. The naps were few and short.

The diary showed that the preceding sleep (before the one recorded) took place between $0627(16 \mathrm{~min})$ and 1233 (55 $\mathrm{min})$ after the night shift [plus $29 \mathrm{~min}$ of napping at $1505(93 \mathrm{~min})]$, between $2340(25 \mathrm{~min})$ and $0818(40 \mathrm{~min}$ ) after the afternoon shift (no napping), and between 2304 (35 $\mathrm{min})$ and $0430(21 \mathrm{~min})$ after the morning shift [plus $17 \mathrm{~min}$ of napping at 1510 $(89 \mathrm{~min})$ ].

Table 2 shows that the SWE changed significantly across the non-REM-REM sleep cycles only for the afternoon condition. SWA and SWS, on the other hand, fell significantly across cycles for all conditions (figure 1). The REM sleep showed a significant variation for the afternoon condition only, with a maximum in the fourth cycle. The cycle duration varied significantly for the afternoon condition only, the highest value appearing in the second cycle.

A Friedman analysis of variance was also carried out to compare the first sleep cycle between the three shifts. For none of the variables listed in table 2 did the chisquare value exceed 5.99 (for $P<0.05$, degrees of freedom 2, $N=14$ ). The same result was obtained when the second and third cycle, respectively, were compared across shifts. We also summed the values across the three first cycles (averaged for SWA) but found no chi-square values above 5.99 (degrees of freedom 2, $N=10$ ). The reduced number of subjects was due to the fact that some of the subjects did not provide three complete sleep cycles.

\section{Discussion}

Considering first the effects on total sleep, the amount and composition of traditional sleep parameters during the night shift showed results similar to those of 
Table 2. Mean and standard error (SE) per non-REM-REM sleep cycle for sleep parameters in connection with afternoon, morning, and night workshifts. ${ }^{a}$ (SWE = slow-wave energy, SWA = slow-wave activity, SWS $=$ slow-wave sleep, REM $=$ rapid-eyemovement)

\begin{tabular}{|c|c|c|c|c|c|c|c|c|c|c|}
\hline \multirow{2}{*}{ Variable } & \multirow{2}{*}{$\begin{array}{l}\text { Number } \\
\text { of } \\
\text { subjects }\end{array}$} & \multicolumn{2}{|c|}{ Gycle 1} & \multicolumn{2}{|c|}{ Cycle 2} & \multicolumn{2}{|c|}{ Cycle 3} & \multicolumn{2}{|c|}{ Cycle 4} & \multirow{2}{*}{$\begin{array}{l}\text { Chi- } \\
\text { square }^{b}\end{array}$} \\
\hline & & Mean & SE & Mean & SE & Mean & SE & Mean & SE & \\
\hline \multicolumn{11}{|l|}{ SWE $(\%)$} \\
\hline $\begin{array}{l}\text { Afternoon shift } \\
\text { Night shift } \\
\text { Morning shift }\end{array}$ & $\begin{array}{l}14 \\
13 \\
10\end{array}$ & $\begin{array}{l}25 \\
24 \\
30\end{array}$ & $\begin{array}{l}2 \\
4 \\
6\end{array}$ & $\begin{array}{l}25 \\
25 \\
27\end{array}$ & $\begin{array}{l}2 \\
4 \\
3\end{array}$ & $\begin{array}{l}21 \\
19 \\
18\end{array}$ & $\begin{array}{l}3 \\
2 \\
3\end{array}$ & $\begin{array}{l}16 \\
\cdot \\
\cdot\end{array}$ & $\begin{array}{l}1^{*} \\
\cdot \\
\cdot\end{array}$ & $\begin{array}{c}12.2^{* *} \\
4.3 \\
5.4\end{array}$ \\
\hline \multicolumn{11}{|l|}{ SWA $(\%)$} \\
\hline $\begin{array}{l}\text { Afternoon shift } \\
\text { Night shift } \\
\text { Morning shift }\end{array}$ & $\begin{array}{l}14 \\
13 \\
10\end{array}$ & $\begin{array}{l}123 \\
126 \\
142\end{array}$ & $\begin{array}{r}7 \\
11 \\
25\end{array}$ & $\begin{array}{l}104 \\
121 \\
122\end{array}$ & $\begin{array}{r}5 \\
15 \\
12\end{array}$ & $\begin{array}{r}102 \\
103 \\
90\end{array}$ & $\begin{array}{r}7 \\
13 \\
10\end{array}$ & $\begin{array}{l}72 \\
\cdot \\
\cdot\end{array}$ & $\begin{array}{l}4^{*} \\
\cdot\end{array}$ & $\begin{array}{l}23.1^{\star \star *} \\
5.9^{\star} \\
9.6^{\star *}\end{array}$ \\
\hline \multicolumn{11}{|c|}{ Total sleep time (min) } \\
\hline $\begin{array}{l}\text { Afternoon shift } \\
\text { Night shift } \\
\text { Morning shift }\end{array}$ & $\begin{array}{l}14 \\
13 \\
10\end{array}$ & $\begin{array}{l}99 \\
86 \\
96\end{array}$ & $\begin{array}{l}7 \\
7 \\
4\end{array}$ & $\begin{array}{r}118 \\
95 \\
101\end{array}$ & $\begin{array}{l}8 \\
7 \\
4\end{array}$ & $\begin{array}{l}93 \\
89 \\
85\end{array}$ & $\begin{array}{l}6 \\
6 \\
3\end{array}$ & $\begin{array}{c}107 \\
\cdot \\
.\end{array}$ & $\begin{array}{l}7 \\
\cdot \\
\cdot\end{array}$ & $\begin{array}{l}9.1^{*} \\
0.6 \\
1.8\end{array}$ \\
\hline \multicolumn{11}{|l|}{ SWS (min) } \\
\hline $\begin{array}{l}\text { Afternoon shift } \\
\text { Night shift } \\
\text { Morning shift }\end{array}$ & $\begin{array}{l}14 \\
13 \\
10\end{array}$ & $\begin{array}{l}41 \\
39 \\
36\end{array}$ & $\begin{array}{l}4 \\
4 \\
4\end{array}$ & $\begin{array}{l}34 \\
33 \\
41\end{array}$ & $\begin{array}{l}4 \\
4 \\
6\end{array}$ & $\begin{array}{l}28 \\
25 \\
13\end{array}$ & $\begin{array}{l}4 \\
4^{\star} \\
3\end{array}$ & $\begin{array}{l}8 \\
\cdot \\
\cdot\end{array}$ & $\dot{2}$ & $\begin{array}{c}14.4^{\star \star *} \\
9.9^{\star \star} \\
13.4\end{array}$ \\
\hline \multicolumn{11}{|l|}{ REM sleep (min) } \\
\hline $\begin{array}{l}\text { Afternoon shifts } \\
\text { Night shift } \\
\text { Morning shift }\end{array}$ & $\begin{array}{l}14 \\
13 \\
10\end{array}$ & $\begin{array}{l}16 \\
17 \\
17\end{array}$ & $\begin{array}{l}3 \\
2 \\
4\end{array}$ & $\begin{array}{l}28 \\
25 \\
19\end{array}$ & $\begin{array}{l}4 \\
5 \\
4\end{array}$ & $\begin{array}{l}15 \\
23 \\
20\end{array}$ & $\begin{array}{l}2 \\
4 \\
4\end{array}$ & $\begin{array}{c}30 \\
\cdot \\
\cdot\end{array}$ & $\begin{array}{l}4^{*} \\
\cdot \\
\cdot\end{array}$ & $\begin{array}{l}11.7^{\star *} \\
1.3 \\
0.1\end{array}$ \\
\hline
\end{tabular}

a Asterisks in connection with the mean values indicate significant (at least $<0.05$ ) deviation from the first sleep cycle (Friedman pairwise comparison with control).

b Chi-square values were computed for the difference between conditions according to the Friedman analysis of variance for ranks $\left.{ }^{*} P<0.05,{ }^{*}{ }^{*} P<0.01, * \star * P<0.001\right)$.

previous studies $(1-8)$. In other words, sleep after the night shift was reduced by more than $2 \mathrm{~h}$, the loss affecting stage 2 and REM sleep mainly and SWS marginally. Thus the prior studies may have, despite their artificial setting, given a rather correct view of the night-shift sleep of shift workers. The morning shift showed very similar effects, a finding which lends support to the data of Tilley et al (8). Parameters such as sleep efficiency, percentage of wakefulness after sleep onset, sleep latency, REM latency, SWS latency, or SWE did not differ between shifts.

The only prior polysomnographic study that has included spontaneous napping is that by Torsvall et al (7), which included the 14 present subjects. In that study 7 out of 25 subjects $(28 \%)$ took naps after the night shift. (The morning shift was not recorded.) These figures correspond closely to the 4 out of 14 $(28 \%)$ in the present study. In addition the total amount and timing of the naps after the night shift were similar in the two studies (a group mean of 12$13 \mathrm{~min}$ ). The present study indicates that the morning shift involves about as much napping as does the night shift. In contrast to the prior study, naps (unintentional) during night work were not observed. The reason was, apparently, that the subjects had been embarrassed by the results of the prior study and made a strong point of not being caught napping during work.

The reason for many of the effects on morning- and night-shift sleep is, very likely, circadian regulation.

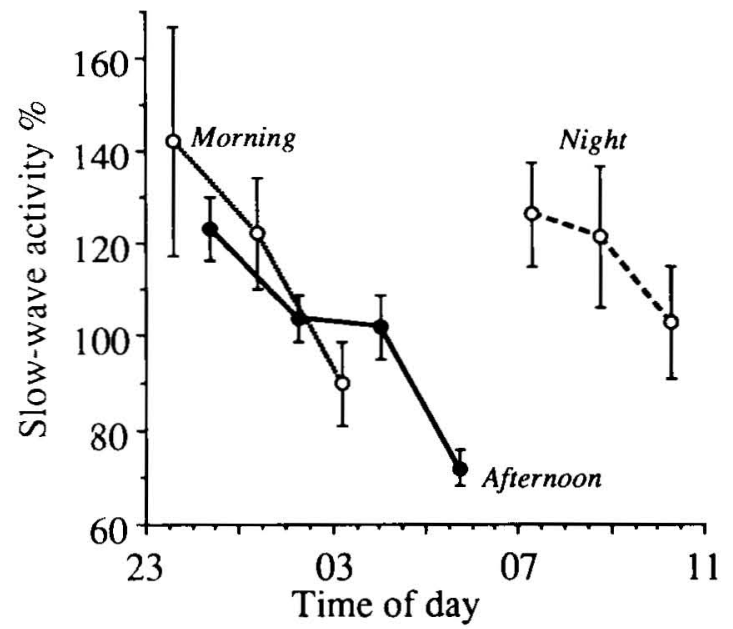

Figure 1. Mean ( \pm 1 standard error) for the percentage of slowwave activity (SWA) per cycle and shift plotted at cycle midpoint. The base line for the percentage was the mean cycle value for the afternoon shift.

We did not record variables to indicate circadian phase, but there is ample evidence that circadian rhythmicity is very little affected by shift work (15). Thus, on the assumption of a rather stable circadian system, the shortened sleep after the night shift in the present study very likely reflected the circadian interference with sleep in the early morning $(16,17)$. This possibility is also supported by the fact that the awakenings were largely spontaneous and subjectively easy, although 
premature (in comparison with the sleep length obtained in connection with the afternoon shift). In contrast, the morning-shift sleep was terminated by external means, and with great difficulty and extremely low levels of "being well rested." It seems likely that the latter was due to the difficulties awakening caused by the circadian nadir of alertness (18). At this circadian phase (0430) sleep is very strongly promoted and spontaneous awakenings are extremely rare (19). The difficulties awakening at this time of day very likely taint the perception of the morning shift in its entirety. The afternoon shift was the least afflicted of the three shifts.

It is interesting to note that the subjective sleep disturbances mainly concerned the duration and termination of sleep, whereas rated sleep quality, restlessness, and sleep latency did not differ between the shifts. The polysomnographic variables showed a similar pattern (ie, the number of awakenings, the amount of stage 1, the amount of wakening after sleep onset, or the sleep latency did not differ significantly between the shifts).

For REM sleep the pattern across cycles was significant only for the afternoon-shift sleep. The reason for the significant pattern may not only have been the extra fourth cycle of that sleep, but also its position in the early morning when REM sleep is normally enhanced (20).

For the SWA and SWS the pattern across cycles was one of decrease, although the morning- and night-shift sleep showed less pronounced patterns, very likely due to their lack of a fourth cycle, in which slow-wave occurrence is rather unusual $(10,21)$. The SWE, however, showed a less pronounced fall than the other two slow-wave variables. The reason was probably that SWE contains a time factor - cycle duration - which did not show any fall across cycles. The pattern of cycle duration is normally one of low values in the first and fifth (last) cycle (22).

The lack of increased total amounts of SWS and SWE in night-shift sleep was expected from prior studies of shift workers (1-8). Admittedly, at first thought, one might expect increased slow-wave levels because of the prior sleep loss involved and its expected effects on SWS or SWE $(10,21,23)$. Nevertheless, the sleep curtailment involved would also prevent an increase of the total amounts of SWS or SWE. A similar reasoning may probably be applied to the morningshift sleep although very little data are available apart from those of the present study (8).

On the other hand, in the present study no significant differences between shifts were obtained even when individual sleep cycles were compared across shifts. Normally, the first sleep cycle is particularly sensitive to prior sleep loss $(10,21,23)$. Similar observations of unresponsive morning and night-shift levels of SWS per cycle, per hour, or per third of sleep have been made in several studies of shift work $(2,3,8$, 24-27).
One explanation for the lack of slow-wave response may be that the amount of sleep deprivation was too small. In the present study the 24 -h period preceding the recorded sleep showed, according to the diary, a sleep loss of about $2 \mathrm{~h}$ and an extension of wakefulness of about $3 \mathrm{~h}$. There seems to be little data available on the effects of a 2-h reduction of sleep on slowwave parameters, but a 4-h reduction seems to have no or marginal effects (28-31). Perhaps an effect should not be expected since $4 \mathrm{~h}$ of sleep curtailment does not normally affect the SWS content of the same sleep episode $(28,31-35)$; thus there would be no SWS loss to recover. A 6-h reduction has, however, a marked effect on subsequent SWS and $\operatorname{SWE}(28,30)$.

With respect to sleep deprivation through extended waking, we know that the SWS and SWA response is essentially exponential $(10,21,23,36)$. Thus, for example, the response to an increase from 0 to $3 \mathrm{~h}$ of waking is considerable, whereas an increase from 15 to $18 \mathrm{~h}$ (as in the present study) is much smaller. A difference between 12 and $20 \mathrm{~h}$ of waking yields a significant SWS difference however (37). Interestingly, most laboratory simulations of night work have failed to find any increased SWS amounts in subsequent day sleep despite the fact that bedtime was postponed by approximately $8 \mathrm{~h}(35,38-43)$. The study by Webb \& Agnew (42) recorded day sleep five times consecutively and found no changes in SWS over this period. Most of the studies did, however, find increased REM sleep during day sleep.

Napping does not seem a likely explanation for the lack of slow-wave response since the mean length of the naps was very short and their slow-wave content was very low in the present study. Significant effects seem to require about $2 \mathrm{~h}$ of napping - taken rather late during the waking span (44-46). In other polysomnography studies of shift-work sleep, napping has usually not been included.

Taken together, both the present and prior studies suggest that shift-work sleep is unaffected by sleep deprivation. A firm conclusion would, however, have to await further data collected with a larger number of subjects and a systematic recording of all sequential shifts, plus days off. The suggestion of a lack of a sleep deprivation effect on sleep also raises the question of the role of sleep loss in bringing about the severe sleepiness that characterizes the night shift (47). The present design did not permit any conclusions in this respect, and, to our knowledge, there are no studies available that have tried to estimate the separate contributions of, for example, circadian phase, sleep curtailment, and time awake to night-shift sleepiness. The latter is seldom discussed as a source of sleepiness among shift workers, but it should be emphasized that the start of day work is preceded by $1-2 \mathrm{~h}$ of wakefulness, whereas the start of night work may be preceded by $10 \mathrm{~h}$ awake. This difference in prior wakefulness very likely causes a substantial reduction in alertness on the night shift (apart from the ef- 
fect of the circadian trough) since alertness falls exponentially across time (48). Subsequent SWS should not differ much since the prior time awake is similar. Obviously, there is a need for studies of the relative importance of different contributors to night-shift sleepiness - the strategy for countermeasures would depend on the result.

In summary, the present study has demonstrated that sleep in connection with night and morning shifts is reduced with respect to the amounts of total sleep time, stage 2 sleep, REM sleep, and SWS, whereas SWE and SWA are only marginally affected. Furthermore, the additional sleep obtained from naps is limited. Subjectively, morning-shift sleep seems to cause the most profound sleep discomfort. On the whole, the results suggest that shift workers' sleep is disturbed, but not to the extent of exhibiting effects of sleep deprivation, at least not in the traditional meaning of the word.

\section{Acknowledgments}

The present study could not have been carried out without the outstanding contributions of the late Lars Torsvall.

This work was supported by the Swedish Work Environment Fund.

\section{References}

1. Foret J, Lantin G. The sleep of train drivers: an example of the effects of irregular work schedules on sleep. In: Colquhoun WP, ed. Aspects of human efficiency. diurnal rhythm and loss of sleep. London: The English Universities Press Ltd, 1972:273-81.

2. Foret $\mathrm{J}$, Benoit $\mathrm{O}$. Etude du sommeil de travailleurs a horaires alternants: adaptation et recuperation dans le cas de rotation rapide de poste (3-4 jours). Eur J Appl Physiol 1978;38:71-82.

3. Matsumoto K. Sleep patterns in hospital night nurses due to shift work: an EEG study. Waking Sleeping 1978;2:169-73.

4. Tepas DI, Walsh JK, Armstrong DR. Comprehensive study of the sleep of shift workers. In: Johnson LC, Tepas DI, Colquhoun WP, Colligan MJ, ed. Biological rhythms, sleep and shift work. New York, NY: SP Medical \& Scientific Books, 1981:347-56.

5. Dahlgren K. Adjustment of circadian rhythms and EEG sleep functions to day and night sleep among permanent night workers and rotating shift workers. Psychophysiology 1981;18:381-91.

6. Torsvall L, Åkerstedt T, Gillberg M. Age, sleep and irregular workhours: a field study with electroencephalographic recordings, catecholamine excretion and selfratings. Scand J Work Environ Health 1981;7:196-203.

7. Torsvall L, Åkerstedt T, Gillander K, Knutsson A. Sleep on the night shift: 24-hour EEG monitoring of spontaneous sleep/wake behavior. Psychophysiology 1989;26:352-8.

8. Tilley AJ, Wilkinson RT, Warren PSG, Watson WB, Drud $M$. The sleep and performance of shift workers. Hum Factors 1982;24:624-41.

9. Feinberg I, Fein G, Floyd TC. EEG patterns during and following extended sleep in young adults. Electroencephalogr Clin Neurophysiol 1980;50:467-76.
10. Borbely AA, Baumann F, Brandeis D, Strauch I, Lehmann D. Sleep deprivation: effects on sleep stages and EEG power density in man. Electroencephalogr Clin Neurophysiol 1981;51:483-93.

11. Dyson RJ, Thornton C, Dore CJ. EEG electrode positions outside the hairline to monitor sleep in man. Sleep 1984;7:180-8.

12. Rechtschaffen A, Kales A. A manual of standardized terminology, techniques and scoring system for sleep stages of human subjects. Bethesda, MD: US Department of Health, Education and Welfare, Public Health Service, 1968.

13. Dijk DJ, Brunner DP, Borbely AA. Time course of EEG power density during long sleep in humans. Am J Physiol 1990;258:R650-61.

14. Siegel S, Castellan Jr NJ. Nonparametric statistics for the behavioral sciences. New York, NY: McGraw-Hill, 1988:

15. Ảkerstedt T. Adjustment of physiological circadian rhythms and the sleep-wake cycle to shift work. In: Monk TH, Folkard S, ed. Hours of work. Chichester: John Wiley, 1985:185-98.

16. Czeisler CA, Weitzman ED, Moore-Ede MC, Zimmerman JC, Knauer RS. Human sleep: its duration and organization depend on its circadian phase. Science 1980; 210:1264-7.

17. Ákerstedt T, Gillberg M. The circadian variation of experimentally displaced sleep. Sleep 1981;4:159-69.

18. Froberg JE, Karlsson CG, Levi L, Lidberg L. Psychological circadian rhythms during a 72-hour vigil. Forsvarsmedicin 1975;II:192-201.

19. Strogatz SH, Kronauer RE, Czeisler CA. Circadian regulation dominates homeostatic control of sleep length and prior wake length in humans. Sleep 1986; 9:353-64.

20. Czeisler CA, Zimmerman JC, Ronda JM, Moore-Ede MC, Weitzman ED. Timing of REM sleep is coupled to the circadian rhythm of body temperature in man. Sleep 1980;2:329-46.

21. Webb WB, Agnew JHW. Stage 4 sleep: influence of time course variables. Science 1971;174:1354-6.

22. Feinberg I, Floyd TC. Systematic trends across the night in human sleep cycles. Psychophysiology 1979;16: $283-91$.

23. Knowles JB, MacLean AW, Salem L, Vetere C, Coulter M. Slow-wave sleep in daytime and nocturnal sleep: an estimate of the time course of "Process S." J Biol Rhythms 1986;1:303-8.

24. Bryden G, Holdstock TL. Effects of night duty on sleep patterns of nurses. Psychophysiology 1973; 10:36-42.

25. Foret J, Benoit O. Structure du sommeil chez des travailleurs a horaires alternants. Electroenceph Clin Neurophysiol 1974;37:337-74.

26. Foret $J$, Benoit $O$. Shiftwork: the level of adjustment to schedule reversal assessed by a sleep study. Waking Sleeping 1978;2:107-12.

27. Dahlgren K. Adjustment of circadian rhythms to rapidly rotating shift work - a field study of two shift systems. In: Reinberg A, Vieux N, Andlauer P ed. Night and shift work: biological and social aspects. Oxford: Pergamon Press, 1981:357-64.

28. Webb WB, Agnew HW. The effects on subsequent sleep of an acute restriction of sleep length. Psychophysiology $1975 ; 12: 367-70$.

29. Tilley AJ. Recovery sleep at different times of the night following loss of the last four hours of sleep. Sleep $1985 ; 8: 129-36$.

30. Ảkerstedt T, Gillberg M. A dose-response study of sleep loss and spontaneous sleep termination. Psychophysiology 1986;23:293-7.

31. Brunner DP, Dijk D-J, Tobler I, Borbely AA. Effect of partial sleep deprivation on sleep stages and EEG power spectra: evidence for non-REM and REM sleep homeostasis. Electroencephalogr Clin Neurophysiol 1990;75:492-9. 
32. Webb WB, Agnew HW. Sleep: effects of a restricted regime. Science 1965;150:1745-7.

33. Johnson LC, MacLeod WL. Sleep and awake behaviour during gradual sleep reduction. Percept Mot Skills 1973;36:87-97.

34. Ảkerstedt T, Gillberg M. Experimentally displaced sleep: effects on sleepiness. Electroencephalogr Clin Neurophysiol 1982;54:220-6.

35. Tilley AJ, Wilkinson RT. The effects of a restricted sleep regime on the composition of sleep and on performance. Psychophysiology 1984;21:406-12.

36. Dijk DJ, Beersma DGM, Daan S. EEG power density during nap sleep: reflection of an hourglass measuring the duration of prior wakefulness. J Biol Rhythms $1987 ; 3: 207-19$.

37. Taub JM, Berger RJ. Sleep stage patterns associated with acute shifts in the sleep-wakefulness cycle. Electroenceph Clin Neurophysiol 1973;35:613-9.

38. Weitzman ED, Kripke DF, Goldmacher D, McGregor $P$, Nogeire C. Acute reversal of the sleep-waking cycle in man. Arch Neurol 1970;22:483-9.

39. Berger RJ, Walker JM, Scott TD, Magnuson LJ, Pollack SL. Diurnal and nocturnal sleep stage patterns following sleep deprivation. Psychonomic Sci 1971;23: 273-5.

40. Webb WB, Agnew HW, Williams RL. Effects on sleep of a sleep period time displacement. Aerosp Med 1971; 152-5.
41. Knauth P, Rutenfranz J. Untersuchungen zum Problem des Schlafverhaltens bei experimenteller Schichtarbeit. Int Arch Arbeitsmed 1972;30:1-22.

42. Webb WB, Agnew HW. Effects of rapidly rotating shifts on sleep patterns and sleep structure. Aviat Space Environ Med. 1978;49:384-9.

43. Hume KI. Sleep adaptation after phase shifts of the sleep-wakefulness rhythm in man. Sleep 1980;2:417-35.

44. Karacan I, Williams RL, Finley WW, Hursch CJ. The effects of naps on nocturnal sleep: influence on the need for stage-1 REM and stage 4 sleep. Biol Psychiatry 1970; $2: 391-9$

45. Tilley A, Donohoe F, Hensby S. Homeostatic changes in slow wave sleep during recovery sleep following restricted nocturnal sleep and partial slow wave sleep recovery during an afternoon nap. Sleep 1987;10:600-5.

46. Knowles JB, Coulter M, Wahnon S, Reitz W, MacLean AW. Variation in process S: effects on sleep continuity and architecture. Sleep 1990;13:97-107.

47. Ákerstedt T. Sleepiness as a consequence of shift work. Sleep 1988;11:17-34.

48. Folkard S, Akerstedt T. A three process model of the regulation of alertness-sleepiness. In: Ogilvie R, Broughton R, ed. Sleep, Arousal and performance: problems and promises. Boston, MA: Birkhauser, (in press).

Received for publication: 23 January 1991 